Horizontal transmission may be prevented by immunisation, either passive or active. Hepatitis B vaccines prepared from antigen in blood are already on the market. The Merck, Sharp, and Dohme vaccine H-B-Vax has now been licensed in Britain for administration to infants; it has been found to be perfectly safe, and adverse reactions have been rare. Such vaccines have already been widely used to protect infants born to mothers who are carriers of hepatitis B. ${ }^{12-20}$ Provided the infants were given their first dose of hepatitis $B$ vaccine at birth, almost all those who would otherwise have become carriers were protected, some schemes and vaccines being more successful than others. Giving hepatitis B immunoglobulin alone often merely delayed the appearance of chronic antigenaemia..$^{21-23}$

The efficacy of vaccine plus immunoglobulin has been compared with that of vaccine alone.$^{13}{ }^{18}$ One study appeared to find better results with the combined treatment, ${ }^{13}$ but the differences were not statistically significant, and equally good results have been obtained in other studies by vaccine alone. ${ }^{12}$ The quality of vaccine is important. An experimental American batch inactivated with formalin alone gave excellent results in a three dose trial in China. ${ }^{19} \mathrm{~A}$ series of four $10 \mu \mathrm{g}$ doses of H-B-Vax given at birth and at 1 month, 2 months, and 6 months gave an excellent antibody response and a high rate of protection. ${ }^{12}$

Most infants who are infected acquire the infection during birth. Sometimes, however, a high titre of antigen is found in the cord blood, reflecting antenatal infection; attempts to protect such babies with immunoglobulin or vaccine or both have failed.$^{20}$ So there is probably no hope of protecting every child. Nevertheless, if we could immunise the entire world population and immunise babies born to carrier mothers at birth, the carriers-and cases-ought to disappear in two generations. A useful discussion of the theory underlying the control of infections by vaccination recently appeared in Nature. ${ }^{24}$

Worldwide immunisation is the ideal; but what can and should we be doing now in a cash limited NHS? If we can afford it we screen all mothers and immunise babies of carriers at birth. Next best-and I believe we should get a very good return for our money-would be to screen all mothers of Chinese and African origin, including West Indian, and, if possible, mothers of Asian origin too. The much larger Birmingham study ${ }^{8}$ does not support the contention that babies born to West Indian mothers are not much at risk. ${ }^{25}$ Hepatitis immune globulin is expensive, and it is in such short supply at present that I do not believe that it ought to be routinely used in addition to the vaccine until someone shows that it improves the results substantially. This has not yet been done.

\section{T H FLEWETT}

Director,

Regional Virus Laboratory,

East Birmingham Hospital,

Birmingham B9 5ST

\footnotetext{
Beasley RP, Hwang L-Y. Post natal infectivity of hepatitis B surface antigen carrier mothers, $\mathcal{f}$ Infect Dis 1983;147:185-90.

2 Beasley RP, Hwang L-Y, Lin CC, Chien C-S. Hepatocellular carcinoma and HBV. A prospective study of 22,207 men in Taiwan. Lancet 1981;ii:1129-33.

Boxall EH. Vertical transmission of hepatitis B. Clin Exper Obstet Gynecol 1983;10:41-8.

4 Ewing CI, Davidson DC. Fatal hepatitis B in infants born to HBsAg carriers with HBeAb. Arch Dis Child 1985;60:265-7.

Boxall $\mathrm{EH}$. Hepatitis problems in the pregnant nursing mother and the newborn. Midwives Chronicle and Nursing Notes 1983;96:226-9.

6 Tong MJ, Sinatra FR, Thomas DW, Nair PV, Merrith RJ, Wong DW. Need for immunoprophylaxis in infants born to $\mathrm{HBs} \mathrm{Ag}$ positive mothers who are $\mathrm{HBe} \mathrm{Ag}$ negative. $\mathrm{f}$ Pediatr 1984;105:945-7.

7 Sinatra FR, Shah P, Weissman JY, Thomas DW, Merritt RJ, Tong MJ. Transmitted acute icteric hepatitis $B$ in infants born to hepatitis B surface antigen positive and anti hepatitis $B$ e positive
} carrier mothers. Pediatrics 1982;70:557-9.
8 Derso A, Boxall EH, Tarlow MJ, Flewett TH. Transmission of $\mathrm{HBsAg}$ from mother to infant in four ethnic groups. Br Med f 1978;i:949-52.

Stevens CE, Beasley RP, Tsiu J, Lee WL. Vertical transmission of hepatitis B antigen in Taiwan (1975). N Engl f Med 1975;292:771-4.

10 Wong VCW, Lee AKY, Ip HMH. Transmission of hepatitis B antigen from symptom-free carrier mothers to their infants. Br f Obstet Gynaecol 1980;87:958-65.

11 Hwang L-Y, Roggendorf M, Beasley RP, Deinhardt F Perinatal transmission of hepatitis B virus: role of maternal HBe Ag and anti HBc IgM. I Med Virol 1985;15:265-9.

12 Boxall $\mathrm{EH}$, Tarlow $\mathrm{MJ}$. Hepatitis $B$ vaccine in the prevention of perinatally transmitted hepatitis $B$ virus infections: initial report of a study in the West Midlands of England. $\mathcal{f}$ Med Virol 986;18:255-60

13 Wong VCW, Ip HMH, Reesink HW, et al. Prevention of the HBs Ag carrier state in newborn infants of e $\mathrm{Ag} \mathrm{HBs}$ carriers by administration of hepatitis B vaccine and HBIG. Lancet 1984;i:921-6.

14 Beasley RP, Hwang LY, Lee GCY, et al. Prevention of perinatally transmitted hepatitis B virus infections with hepatitis B immunoglobulin and hepatitis B vaccine. Lancet 1983;ii:1099-102.

5 Barin F, Denis F, Chiron JP, et al. Immune response in neonates to hepatitis B vaccine. Lancet 1982;i:251-3.

16 Goudeau A, Lo K-J, Coursaget $P$, et al. Prevention of hepatitis B virus infection in children born to $\mathrm{HBs}$ Ag positive/ $\mathrm{HBe} \mathrm{Ag}$ positive mothers. Dev Biol Stand 1983;54:399-404.

17 Zanetti AR, Dentico P, Blanco CDV, et al. Multicentre trial on the efficacy of HBIG and vaccine in preventing perinatal hepatitis B. Final report. $\mathcal{F}$ Med Virol 1986;18:327-34.

18 Esteban JI, Genesca J, Esteban R, et al. Immunoprophylaxis of perinatal transmission of the hepatitis B virus: efficacy of hepatitis B immune globulin and hepatitis B vaccine in a lowhepatitis B virus: efficacy of hepatitis B im

19 Xu Z-Y, Liu CB, Francis DP, et al. Prevention of perinatal acquisition of hepatitis B carriage using vaccine; preliminary report of a randomized double blind placebo-controlled and comparative trial. Pediatrics 1985;76:713-8.

20 Stevens CE, Toy PT, Tong MJ, et al. Perinatal hepatitis B virus transmission in the United States. Prevention of passive-active immunization. JAMA 1985;253:1740-5.

21 Beasley RP, Hwang L-Y, Stevens CE, et al. Efficacy of hepatitis B immunoglobulin for prevention of perinatal transmission of the hepatitis B virus carrier state. Hepatology 1983;3:125-41.

22 Reesink HW, Reerink-Brongers EE, Lafeber-Schut BJT, Benschop KJ, Brummelthuis HGJ. Prevention of chronic $\mathrm{HBs} \mathrm{Ag}$ carrier state in infants of $\mathrm{HBs} \mathrm{Ag}$ positive mothers by hepatitis $\mathrm{B}$ immunoglobulin. Lancet 1979;ii:436-8.

23 Boxall EH, Flewett TH, Derso A, Tarlow MJ. Specific immunoglobulin for babies born to $\mathrm{HBsAg}$ carrier mothers. Lancet 1980;i:419-20.

24 Anderson RM, May RM. Vaccination and herd immunity of infectious diseases. Nature 1985;318:323-9.

25 Godly MJ, Laidler PW, Banatvala JE. Hepatitis B in a West Indian population in the United Kingdom. Br Med F 1986;292:375.

\section{Dangers of snuff, both "wet" and "dry"}

Around $220000 \mathrm{~kg}$ of snuff is still manufactured each year in Britain. This represents less than $1 \%$ of tobacco consumption, but snuff carries no excise duty, and with cigarette smoking in decline attempts are being made to repopularise the habit of snuff taking. There have also been recent attempts to introduce Skoal Bandits (tobacco "teabags") into Britain. Just how dangerous are these alternative ways of taking tobacco?

Russell et al measured blood concentrations of nicotine and cotinine in dedicated snuff users and found results comparable with those of smoking a single cigarette. ${ }^{2}$ Absorption from the nasal mucosa was rapid, though the intake was related to the experience of the snuffer. In some ways this rapid absorption is surprising because of the changes within the nasal passages of experienced snuffers. I described these in 1964 and have now examined 63 people who had used commercial snuff for at least 10 years. ${ }^{2}$ All showed generalised atrophy of both middle and inferior turbinals with lumps of snuff lying in the middle meatus. Biopsies showed metaplasia from the usual ciliated columnar to squamous epithelium over a widespread area, but in no case had a malignant neoplasm developed. No history of snuff using was recorded in any of the 265 patients treated for upper jaw malignancy during a 20 year period.

Since nasal snuff is unburnt it contains-in contrast to tobacco smoke-no tar, carbon monoxide, or oxides of nitrogen. Since it is not inhaled it cannot carry a risk of lung cancer, but what is the risk of local damage? Root, Aust, and Sullivan reported the case of a farmer who had placed snuff in the left ear for 42 years, eventually developing a squamous carcinoma of the external auditory meatus. ${ }^{3}$ 
Though I have never seen nasal or antroethmoidal cancer arising in any patient within Britain who had used snuff, it is a possible explanation for the extraordinarily high incidence of upper jaw neoplasms in the Bantu tribes of the Transvaal, among whom the use of indigenous snuff is widespread. Campbell and Cooper found as much 3:4 benzpyrine in Zulu snuff, which contains charred aloe stems as well as tobacco, as in cigarette smoke condensate. ${ }^{+}$Epidemiological studies, and my own observations in South Africa, support the view that prolonged usage of this carcinogenic snuff is the prime aetiological factor in the production of this highly malignant neoplasm.

Within the United States and Scandinavia snuff dipping is the predominant form of snuff use. "Wet snuff" is placed between the lower lip or buccal mucosa and gums. In many ways this is similar to the use of "pan" or the many other tobacco concoctions that are used within the mouth throughout central and southern Asia. All contain tobacco, but "wet" snuff contains not only nitrosonornicotine but at least 19 other varieties of nitrosamines as well as polycyclic aromatic hydrocarbons. Perhaps more important than chemical analysis and animal experiments of doubtful relevance is the epidemiological evidence of a high incidence of carcinoma at the site of these "implants." In Ceylon and Bombay, where the quid is between cheek and gum, so is the cancer. Where it is held under the tongue, half the cancers affect the anterior tongue. Similar evidence has been available for many years from studies within the southern states of the United States. Snuff dipping has long been a popular practice in these regions, particularly among women. Rosenfield and Callaway found that $90 \%$ of their women patients with oral cancer were habitual users of snuff. ${ }^{5}$ This association has been recognised by most surgeons working in these areas but it is important to remember that such patients may have used snuff for as long as 40 to 60 years. When there is an association with pungent diet, poor oral hygiene, and malnutrition the incidence of cancer may be even higher and the period of exposure much shorter. In my personal experience of 117 patients with cancer of the buccal mucosa, anterior tongue, or floor of mouth I have found a history of snuff dipping only in those from Asia or India. Fortunately dipping is not common in the indigenous or immigrant populations of Britain.

In the United States there is some evidence of a move among young people from cigarette smoking to chewing tobacco or snuff dipping, and this is now threatening in Britain. We should remember that the local effects of snuff on the gums are well recognised-as is the risk of nicotine addiction in the young. Some people seem not to accept that the long term carcinogenic effects of snuff in the mouth would be the same in Britain as those already documented in the United States as well as elsewhere in the world. The time scale may prove to be longer than for tobacco induced lung cancer, but the results of treatment of oral cancer are little better. Tobacco in all its forms is dangerous, and subtle advertising campaigns should not be allowed to confuse the issue. The United Kingdom Coordinating Committee in Cancer Research called last week ( $p 000$ ) for a ban on the import, manufacture, and sale of snuff.

D F N HARRISON

Professor of Laryngology and Otology,

Institute of Laryngology and Otology,

London WCIX 8EE

\footnotetext{
I Russell MAM, Jarvis MS, Devitt G, Feyerabend C. Nicotine intake by snuff users. Br Med $\mathcal{J}$ 1981;283:814-7.

2 Harrison DFN. Snuff-its use and abuse. Br Med f 1964;ii:1649-51.

3 Root HD, Aust JB, Sullivan A. Snuff and cancer of the ear. N Engl f Med 1960;262:819-20.

4 Campbell JM, Cooper RL. The presence of 3.4 Benzypyrine in snuff associated with a high incidence of cancer. Chemistry and Industry 1955;33:64-6.
}

5 Rosenfeld L, Calloway J. Snuff dippers cancer. Am 7 Surg 1963;106:840-4

\title{
Management of infection in the neutropenic patient
}

\author{
ROBERT E MARCUS, JOHN M GOLDMAN
}

Some reversible depression of the bone marrow is an inevitable consequence of many chemotherapy regimens used in oncology. Such periods of neutropenia are usually short; if prolonged they would probably lead to reduction in the dosage of cytotoxic drugs for later courses. In the management of acute leukaemia, however, and more recently in lymphoma and some solid tumours long periods of marrow hypoplasia and neutropenia are the consequence of deliberate attempts to maximise the kill of tumour cells.

These periods of neutropenia, lasting up to four weeks, are also seen after autologous and allogeneic bone marrow transplantation and carry the risk of severe bacterial, fungal, and viral infection. The incidence and severity of these infections are greater than those seen in chronic neutropenic states such as aplastic anaemia since chemotherapy and radiotherapy damage the membranes of the oropharynx, gut, and lung and thereby permit predominantly Gram negative organisms to enter the systemic circulation or the lung parenchyma more readily. By contrast patients with neutropenia due to severe aplastic anaemia rarely suffer from serious infections with Gram negative organisms, their frequency being related to the absolute monocyte count. ${ }^{1}$

This combination of damage to membranes and suppression of residual haemopoiesis renders patients with leukaemia particularly susceptible to severe infections, many of which are due to endogenous gastrointestinal organisms. ${ }^{2}$ This has led several groups to attempt to reduce the level of microbial flora in the gut with combinations of non-absorbable antibiotics. ${ }^{3}$ Some centres persist with this approach, but many have rejected it for three reasons: firstly, the necessary 